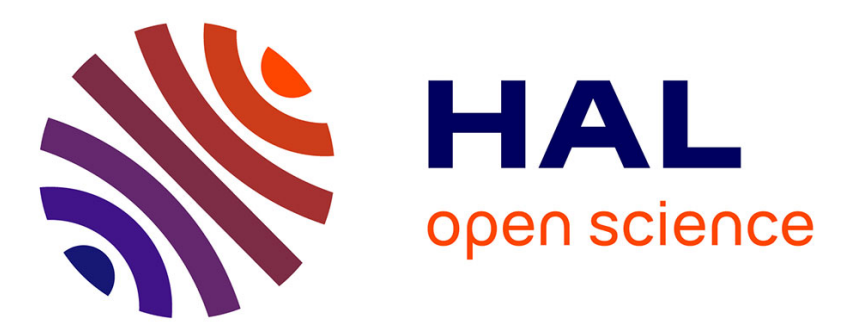

\title{
Epidemiological surveillance of lumbar disc surgery in the general population: a pilot study in a French region.
} Yves Roquelaure, Natacha Fouquet, Catherine Ha, Éric Bord, Nathalie Surer, Audrey Petit, Annette Leclerc, Pierre Lombrail, Marcel Goldberg, Ellen Imbernon

\section{To cite this version:}

Yves Roquelaure, Natacha Fouquet, Catherine Ha, Éric Bord, Nathalie Surer, et al.. Epidemiological surveillance of lumbar disc surgery in the general population: a pilot study in a French region.. Joint Bone Spine, 2011, 78 (3), pp.298-302. 10.1016/j.jbspin.2010.08.008 . hal-03390174

\section{HAL Id: hal-03390174 \\ https://univ-angers.hal.science/hal-03390174}

Submitted on 21 Oct 2021

HAL is a multi-disciplinary open access archive for the deposit and dissemination of scientific research documents, whether they are published or not. The documents may come from teaching and research institutions in France or abroad, or from public or private research centers.
L'archive ouverte pluridisciplinaire HAL, est destinée au dépôt et à la diffusion de documents scientifiques de niveau recherche, publiés ou non, émanant des établissements d'enseignement et de recherche français ou étrangers, des laboratoires publics ou privés. 


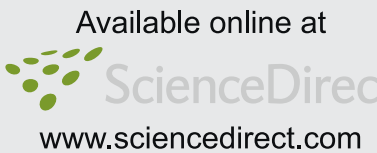

\title{
Epidemiological surveillance of lumbar disc surgery in the general population: A pilot study in a French region
}

\author{
Yves Roquelaure ${ }^{\mathrm{a}, *}$, Natacha Fouquet ${ }^{\mathrm{a}, \mathrm{b}},{\text { Catherine } \mathrm{Ha}^{\mathrm{b}} \text {, Éric Bord }}^{\mathrm{c}}$, Nathalie Surer ${ }^{\mathrm{d}}$, \\ Audrey Petit Le Manach ${ }^{\mathrm{a}}$, Annette Leclerc ${ }^{\mathrm{e}}$, Pierre Lombrail ${ }^{\mathrm{d}}$, Marcel Goldberg ${ }^{\mathrm{b}}$, Ellen Imbernon ${ }^{\mathrm{b}}$ \\ a IFR 132, UPRES 4336, UNAM, laboratoire d'ergonomie et d'épidémiologie en santé au travail, CHU, université d'Angers, 4, rue Larrey, 49933 Angers cedex, France \\ ${ }^{\mathrm{b}}$ Département santé travail, institut de veille sanitaire, 94415 Saint-Maurice, France \\ ${ }^{c}$ Pôle neurosciences, $\mathrm{CHU}$ de Nantes, 44000 Nantes, France \\ d PIMESP, CHU, 44000 Nantes, France \\ e Inserm, U1018, 16, avenue Paul-Vaillant-Couturier, 94807 Villejuif, France
}

\section{A R T I C L E I N F O}

\section{Article history:}

Accepted 9 August 2010

Available online 28 September 2010

\section{Keywords:}

Sciatica

Herniated disc

Low back pain

Attributable risk

Occupation

Work-related

\section{Introduction}

Disc related sciatica (DRS) is a frequent public health problem leading to major socioeconomic costs. Its prevalence is estimated to be about 5 to $10 \%$ of that of low back pain [1], but wide variations in point prevalence (ranging from 1.6 to $13 \%$ ) and lifetime incidence (ranging from 12 to $43 \%$ ) have been reported depending on the definition used and the population involved [1-3]. Although not caused only by work, DRS represents a major proportion of low back work-related diseases in France, as in many other countries $[1,3,4]$, with about 2500 cases receiving compensation every year in France. Despite the high burden of disease, no French surveillance data on work-related musculoskeletal disorders (MSDs) were available for the working population before 2002, except for Workers' Compensation claim statistics. The French Institute for Public Health Surveillance, therefore, implemented a multilevel epidemiological surveillance system for work-related MSDs in the Pays de la Loire region ( $5 \%$ of the French working population) [5]. Information

\footnotetext{
* Corresponding author. Tel.: +332 41353764.

E-mail address: YvRoquelaure@chu-angers.fr (Y. Roquelaure).
}

on the work-relatedness of herniated discs is still limited. Several individual characteristics (e.g., weight, height, smoking habits and genetic factors) are known to increase the risk of disc herniation [4], as are also occupational risk factors, such as high physical workload, manual material handling, working in a flexed or twisted trunk position or with arms above shoulder level [4-7], driving and exposure to whole-body vibrations [8-11]. Since genetic factors and many individual risk factors for sciatica are not or are less modifiable than workplace factors, information about the occupations and industries in which workers develop sciatica is essential to target prevention strategies in the population.

We have previously reported results of the surveillance of carpal tunnel syndrome in the French general population that provided useful information on the attributable risk of CTS according to occupation and helped policy makers to target preventive intervention programs [5]. The second stage of the multilevel surveillance program was the implementation of a sentinel event system for the surveillance of DRS [5]. Among the potential sources of information, workers' compensation data was impaired by considerable underreporting and did not allow precise assessment of DRS [12]. Neither the cases of DRS diagnosed in primary care settings nor DRS with disc herniation confirmed by CT-scan or MR imaging were system- 
atically registered in France. The main source of usable information, therefore, appeared to be the French hospital database (PMSI) that systematically registers hospital discharges for DRS. However, the coding of hospital stays for conservative treatment of DRS may be imprecise, depending on the coding strategy for non-specific and specific DRS followed by rheumatologists. Hospital discharges following lumbar disc surgery performed in specialized spine centers thus appeared to be the best available sentinel event for the surveillance of DRS. Using the PMSI database for 2003, the annual rate of lumbar disk surgery (LDS) was estimated at 60 per 100,000 persons in the French general population ( 72 per 100,000 for men and 49 per 100,000 for women), with slight variations between regions [French Institute for Public Health Surveillance, data not published]. These estimates were in line with those reported in the USA and Nordic countries [13-16]. We conducted a pilot study in the general population of one district of the region to evaluate the feasibility of the surveillance system for LDS before its extension to the whole region. Our aim in this study was to describe the surveillance system and its ability to assess the risk and the attributable fraction of risk of LDS according to occupation categories and industry sectors.

\section{Methods}

\subsection{Protocol}

\subsubsection{Population}

The population base for this study was defined as all residents of the Loire-Atlantique region between the ages of 20-59 [307,822 women (49.8\%) and 309,861 men (50.2\%)]. According to French National Institute of Statistics and Economic Studies (INSEE) census of 1999, the economic structure was diversified and was similar overall to that of most French regions, except Paris - Îlede-France. The annual rates of disc surgery were 66 per 100,000 for men and 49 per 100,000 for women in this region [data not published].

\subsubsection{Inclusion and data collection procedure}

The pilot study was undertaken in the spine clinics of the University Hospital of Nantes (one of the four spine centers of the region) that performs about $38 \%$ of the lumbar disc surgery for the region's inhabitants (36\% for men and $43 \%$ for women) [data for the years 2002-2003]. We limited the study to patients residing in the catchment area hospitalized between 1st January 2002 and 31st December 2003 (hospital admission dates).

The standardized medical outcome summaries entered on the PMSI database for each hospital stay for LDS were collected. This summary contains administrative data (name, sex, birth date and dates of hospital admission/discharge) and main clinical information, such as main diagnosis, comorbidities and medical or surgical procedures coded according to the International Classification of Diseases, 10th revision (ICD 10th) and the French classification of surgical procedures. From this database, we first extracted the hospital admissions of subjects aged 20 to 59 having undergone lumbar or sacral discectomy for disc-related radiculopathy in the spine center during the study period. Admissions for the following diagnoses were selected: ICD-10th codes M511 (lumbar and other disc disorders with radiculopathy), M512 (other specified intervertebral disc displacement), M518 (other specified intervertebral disc disorders) and M519 (intervertebral disc disorders, unspecified). Hospital admissions were eligible for the study only if the surgical procedure included conventional lumbar discectomy or microendoscopic lumbar discectomy. Patients were definitively included only if they had not undergone previous back surgery. Each eligible patient was informed of the study by his surgeon and received a consent form and a questionnaire by mail. Information was col- lected on medical and surgical history and employment history (industry, occupation and description of tasks throughout employment).

\subsection{Analysis}

Each occupation throughout employment was coded with the two-digit (31 classes studied) French classification of occupations (PCS codes). The analysis was performed on the occupation at the time of LDS. Age- and gender-specific annual incidence rates were computed for employed patients according to each occupational category (or industry sector), with the number of patients having undergone LDS in 2002 or 2003 as numerator. The denominator was the number of persons of the same age, gender and occupational category (or industry sector) in the general population of the LoireAtlantique region. Denominator computation was performed with the database of the last available INSEE census (1999) at the time of the study, assuming that the general population remained stable.

The age-adjusted relative risks (RR) of LDS according to occupation category (or industry sector) were computed using the Mantel-Haenszel method with the whole sample of subjects included in the study as reference, whether they were employed at the time of LDS or not. The non-working subjects included subjects who had never worked, mainly women, pensioners, and all unemployed subjects at the time of LDS. The population attributable fraction of risk (PAF [\%]) to work in the occupation category under consideration was subsequently computed using the following formula:

$P A F=P e(R R-1) /[P e(R R-1)+1]$

The PAF takes into consideration the proportion of subjects in the general population (Pe [\%]) and represents the proportion of cases of LDS in the whole population for each gender, which could theoretically be avoided if the occupation category under consideration did not expose a worker to an excess risk of LDS [17].

\section{Results}

A total of 272 inpatients ( 119 men and 153 women) were included in the pilot study. Their mean age was 42.2 years $(\mathrm{SD}=10.2$ ) without differences between genders. The response rate to the mailed questionnaire was higher for men than for women (59.7\% vs $49.1 \%, P<0.01$ ). Responders were older than the others (43.4 years [SD $=9.5$ ] vs 40.4 [SD $=10.5], P<0.05$ ). Information on employment was available for the 75 women and 71 men, but not for the non-responding patients.

Mean age did not differ between genders. Fifty-four women and 62 men were employed at the time of the lumbar disc surgery, and 21 women and 9 men were unemployed. The mean length of employment in the last job was high (12.4 years, $S D=10.7)$, without difference between genders. Most men (97\%) and women (87\%) had had the same job for the preceding 5 years. If not, most workers remained in the same industry sector or occupation category.

Cases of LDS were identified in 24 occupation categories (out of a total of 31 represented in the region), mainly government employees, nurses, employees in commerce for women and skilled and unskilled industrial blue collar workers, drivers and skilled craft workers for men. No significant excess risk of LDS was observed for farmers, craftsmen, salesmen and managers, or for professionals of both genders (Table 1 ). In contrast to men, excess risk of LDS was observed in female technicians and intermediate occupations $(R R=2.1)$. Lower grade services, sales and clerical white-collar workers were at high risk of $L D S(R R=1.8$ for women and $R R=3.6$ for men). High risk in blue-collar workers $(R R=2.4)$ occurred only for men. The more detailed 2-digit classification of 
Table 1

Incidence, age-adjusted relative risks and population attributable risk fractions of lumbar disc surgery (PAF) according to occupation category in the general population ${ }^{\mathrm{a}}$.

\begin{tabular}{|c|c|c|c|c|}
\hline & $\operatorname{Pe}(\%)^{b}$ & $n$ & Age-adjusted RR [CI 95\% $]^{\mathrm{c}}$ & $\operatorname{PAF}(\%)[\text { range }]^{\mathrm{d}}$ \\
\hline \multicolumn{5}{|l|}{ Women } \\
\hline 1. Farmers & 1.1 & 0 & - & - \\
\hline 2. Craftswomen, saleswomen and managers & 2.4 & 0 & - & - \\
\hline 3. Upper white-collar and professionals & 5.3 & 6 & $2.5[1.0-5.9]$ & - \\
\hline 4. Technicians and intermediate occupations & 11.7 & 14 & $2.1[1.1-4.0]$ & $12[2-26]$ \\
\hline 43. Intermediate occupations in health and social work & 4.5 & 7 & $2.9[1.3-6.4]$ & $8[1-20]$ \\
\hline 5. Lower white-collar workers & 32.5 & 30 & $1.8[1.1-3.1]$ & $22[4-40]$ \\
\hline 52. Employees of government and public services & 11.1 & 16 & $2.7[1.5-4.7]$ & $16[5-29]$ \\
\hline 56. Personal service employees & 7.9 & 7 & $1.9[0.8-4.2]$ & - \\
\hline 6. Blue-collar workers & 6.5 & 4 & - & - \\
\hline \multicolumn{5}{|l|}{ Men } \\
\hline 1. Farmers & 2.5 & 0 & - & - \\
\hline 2. Craftsmen, salesmen and managers & 6.2 & 6 & $2.2[0.9-5.2]$ & - \\
\hline 3. Upper white-collar and professionals & 11.8 & 6 & $0.8[0.4-2.0]$ & - \\
\hline 4. Technicians and intermediate occupations & 22.0 & 7 & $0.6[0.3-1.4]$ & - \\
\hline 5. Lower white-collar workers & 8.3 & 8 & $3.6[1.6-8.5]$ & $18[5-38]$ \\
\hline 6. Blue-collar workers & 30.5 & 34 & $2.4[1.4-4.0]$ & $30[12-48]$ \\
\hline 62. Skilled manufacturing workers & 8.8 & 12 & $2.5[1.3-4.7]$ & $11[3-24]$ \\
\hline 64. Drivers & 3.4 & 7 & $3.9[1.8-8.8]$ & $9[3-21]$ \\
\hline 67. Unskilled manufacturing workers & 5.1 & 7 & $3.9[1.6-9.6]$ & $13[3-31]$ \\
\hline
\end{tabular}

a Patients employed at time of lumbar disc surgery ( 54 women and 62 men, missing occupational category for one man).

b $\mathrm{Pe}(\%)$ : percentage of the general population of the region in this occupation.

c RRs were computed when at least five cases were diagnosed, with the whole sample of subjects, employed or unemployed during the year of lumbar disc surgery as reference group; 95\% confidence interval.

d This range was computed using the lower and higher limits of the confidence interval of the RR of LDS in equation (1) (See the text for details).

occupations showed that the excess risk for the male blue collar workers mainly involved routine occupations, such as skilled $(\mathrm{RR}=2.5)$ and unskilled manufacturing workers (e.g., packers and machine operators) $(R R=3.9)$, and drivers ( $R R=3.9)$. The high risk among female intermediate occupations in health and social work mainly involved nurses $(R R=2.9)$. The risk was also high for lower-grade white-collar employees, mainly employees of government and public services, (e.g., nurses' aides and hospi- tal cleaners) $(R R=2.7)$ and personal services (e.g., personal care workers) $(\mathrm{RR}=1.9)$. The PAF of LDS was 30\% [12-48] for male blue-collar workers, suggesting that about $30 \%$ of the cases occurring in this category of workers could theoretically be avoided if the excess risk of LDS could be eliminated. The PAF for male and female lower white-collar workers and female intermediate occupations were 18 [5-38], 22 [4-40] and 12\% [2-26], respectively.

Table 2

Incidence, age-adjusted relative risks and population attributable risk fractions of lumbar disc surgery (PAF) according to industry sector in the general population ${ }^{\mathrm{a}}$.

\begin{tabular}{|c|c|c|c|c|}
\hline & $\operatorname{Pe}(\%)^{\mathrm{b}}$ & $n$ & Age-adjusted RR [CI 95\% $]^{c}$ & PAF (\%) [range $]^{\mathrm{d}}$ \\
\hline \multicolumn{5}{|l|}{ Women } \\
\hline Agriculture, forestry and fishing & 1.8 & 0 & - & - \\
\hline Manufacturing industries & 6.1 & 6 & $3.7[1.5-9.3]$ & $14[3-34]$ \\
\hline Construction & 0.7 & 0 & - & - \\
\hline Wholesale and retail trade & 8.3 & 5 & $1.4[0.9-3.6]$ & - \\
\hline Hotels and restaurants & 2.6 & 4 & - & - \\
\hline Transport, storage and communication & 2.8 & 2 & - & - \\
\hline Financial intermediation activities & 2.1 & 0 & - & - \\
\hline Temporary work and services to industry & 6.3 & 2 & - & - \\
\hline Public administration & 6.8 & 4 & - & - \\
\hline Education & 6.9 & 8 & $2.1[1.0-4.5]$ & 7 [9-19] \\
\hline Human health and social activities & 13.8 & 21 & $2.5[1.5-4.3]$ & $17[6-31]$ \\
\hline Personal services activities & 3.4 & 1 & - & - \\
\hline \multicolumn{5}{|l|}{ Men } \\
\hline Agriculture, forestry and fishing & 4.0 & 2 & - & - \\
\hline Manufacturing industries & 18.2 & 15 & $1.3[0.7-2.4]$ & - \\
\hline Construction & 7.8 & 8 & $2.0[1.0-4.4]$ & $8[0-21]$ \\
\hline Wholesale and retail trade & 10.5 & 5 & $1.6[0.6-4.0]$ & - \\
\hline Hotels and restaurants & 2.1 & 1 & - & - \\
\hline Transport, storage and communication & 6.4 & 11 & $2.6[1.3-4.9]$ & $9[2-20]$ \\
\hline Financial intermediation activities & 1.9 & 2 & - & - \\
\hline Temporary work and services to industry & 10.1 & 4 & - & - \\
\hline Public administration & 6.0 & 4 & - & - \\
\hline Education & 3.9 & 2 & - & - \\
\hline Human health and social activities & 3.7 & 5 & $6.1[2.2-16.6]$ & $16[4-36]$ \\
\hline Personal services activities & 2.3 & 1 & - & - \\
\hline
\end{tabular}

a Patients employed at time of lumbar disc surgery (54 women and 62 men, missing industry sector for one woman and two men).

b $\mathrm{Pe}(\%)$ : percentage of the general population of the region in this occupation.

c RRs were computed when at least five cases were diagnosed, with the whole sample of subjects, employed or unemployed during the year of lumbar disc surgery as reference group; 95\% confidence interval.

d This range was computed using the lower and higher limits of the confidence interval of the RR of LDS in equation (1). 
Individuals who had undergone LDS worked in 35 different industry sectors (out of a total of 58 represented in the region). The construction $(R R=2.0)$, transport $(R R=2.6)$ and human health and social work $(R R=6.1)$ sectors were at high risk of LDS for men and the sectors at risk for women were the manufacturing industries $(R R=3.7)$, wholesale and retail trade $(R R=1.4)$, human health and social work $(R R=2.7)$ and education $(R R=2.1)$ sectors (Table 2$)$. The PAFs of lumbar disc surgery ranged between 7 and $17 \%$ in these high risk sectors for women and between 8 and 16\% for men.

\section{Discussion}

This pilot study showed the feasibility of a surveillance system for DRS in the general population-based on the registration of hospital discharge following LDS. Wide variations in the relative risks of LDS according to occupations and industry sectors were observed, suggesting that such a system might help policy makers to target preventive measures for occupations and industry sectors at high risk. The population studied included all inhabitants of the region, whether working or not, and covered all occupations and industry sectors. Hospitalization for LDS registered in the French hospital information system (PMSI) was chosen as sentinel event for herniated discs in the absence of accurate administrative information for sciatica requiring conservative treatment. We, therefore, studied the hospital discharges following disc surgery registered in the PMSI database of a large university hospital, which covers almost $99 \%$ of all hospital discharges with high accuracy compared to hospital patients' records.

The outcome chosen for surveillance (i.e., DRS requiring disc surgery) is better defined than signs of radiculopathy assessed by the questionnaire used [3]. However, one essential question is whether this event reflects the incidence of DRS in the population, since the numbers of patients suffering from DRS and not undergoing surgery for disc herniation cannot be established in France. Back surgery rates are known to vary between countries and even regions for several reasons [16], including lack of scientific evidence, financial incentives and disincentives for surgical intervention, differences in clinical training, professional opinion and patients' preferences [15]. The level of education and the socioeconomic status may have intervened $[15,18]$. It is possible that manual workers in our study encountered more difficulties in coping with back pain at work, and this may have led to increased use of health care and surgical treatment $[6,15,18,19]$. Another possible bias may have been in workers' perceptions of their working conditions as poor, thus leading to greater probability of medical consultation or even surgical treatment [8]. Socioeconomic differences in how physicians evaluate patients' needs for surgery can lead to a bias in medical decisions [20], but it has been shown that differences in severe back pain according to socioeconomic class were not due to socioeconomic differences in healthcare use [21]. Nevertheless, the rates of disc surgery computed in the region used for this pilot study were close to those in France (data not shown), suggesting that no particular features of healthcare use or medical practice could explain our results.

It should be pointed our that work exposure was appraised at the levels of industry and job-title, without in-plant job analysis, and therefore, no precise assessment of the actual exposure to biomechanical and psychosocial risk factors of DRS was undertaken. The collection and coding of occupational and economic activity information was based on detailed information about employment and tasks using methodology comparable to that of the INSEE census. Classification bias was minimized by the high proportion of patients being actively employed at the time of the surgical intervention and the length of service in the most recent job. Moreover, where occupational changes occurred during the 5-year period before surgery, there were very few shifts from one occupational category (or industrial sector) to another.

In this pilot study, we restricted the investigation of the surveillance protocol to only one spine center. This may have led to an underestimation of the incidence of LDS, despite its wide catchment area. No significant age differences were observed between patients included in the study and those treated surgically in the other four spine centers, and thus estimates of relative risk of LDS according to age should be unbiased even if the incidence was underestimated. Women were overrepresented in our study, possibly explained by the higher inclusion of nurses and nurses' aides working in the University Hospital. This was observed in Finnish health care workers [15] and could have led to overestimation of the risk for hospital employees and the health sector. The low participation rate overall (57\%), with differences between genders, might have introduced a selection bias, and we cannot exclude the possibility of selection bias of patients according to employment status or occupational class. Nevertheless, the University Hospital is the largest spine center in the region and receives patients from all towns and socioeconomic categories. Thus, selection bias alone would probably not explain our results.

The computation of the PAFs assumed several hypotheses, namely a causal relationship between the occurrence of lumbar disc herniation (and lumbar disc surgery) and work exposure. The reference group was enlarged to the whole sample of subjects, which underestimated the age-adjusted RRs and the PAFs of LDS in specific industries and occupation categories, because the comparison group included a substantial proportion of industrial and occupational groups at significantly high risk of LDS. The lack of statistical power due to the small number of incident cases reduced the accuracy of estimates of RR and PAF, and some industries and occupations associated with lower RR might not have been identified. Analyses took into account age and gender, but not other potential confounding factors related to occupational and non-occupational risk factors for DRS $[15,18]$. In particular, no information was available on non-occupational physical activities, such as housework, second jobs, non-professional driving, leisure and sports activities. Some of these (e.g., housework for women) may be more prevalent in categories with the lowest incomes, and, therefore, be a confounding factor for the association between LDS and lowergrade occupations. However, except for sex and age, which were taken into account in the analyses, non-occupational causes of sciatica seem unlikely to play a major role as confounding factors $[3,6,22]$.

These preliminary findings were in line with the epidemiological literature on DRS. The excess risk of LDS for lower occupational categories (blue collar workers for men and lower services, sales, and clerical white collar workers for women) is consistent with the occupational category distribution of severe low back pain leading to hospitalization or back surgery $[6,11,15,23]$. Our results confirm the excess risk of sciatica previously reported in industrial workers, material handlers, machine operators $[24,25]$, drivers $[3,9,10]$ nurses and nurses' aides [26], and service and nursing home workers [27]. The sectors highlighted by this study are in accordance with previous studies [2,14,27].

To our knowledge, very little has been published on the population attributable fraction of disc-related sciatica and nothing on the PAF of LDS. The estimates we computed are in line overall with those reported by the WHO Global Burden of Disease project for low back pain [7\% (21-41)] [28]. Assuming that other risk factors remain unchanged and that there is a causal relationship between work exposure and sciatica, the population attributable fractions of sciatica to work in high risk occupations should reveal the proportion of sciatica cases that might be prevented following reduction of risk in the workplace [17]. This indicator is useful from a public 
health viewpoint to help policy makers to implement preventive measures. This pilot study demonstrates the feasibility of a surveillance program using LDS as sentinel event for DRS in the general population. This system could provide information on the distribution of LDS according to occupations and industry sectors and the work-related PAF in the general population. Such information would be valuable for public policy.

\section{Conflicts of interest statement}

None of the authors has any conflicts of interest to declare.

\section{References}

[1] Koes BW, Van Tulder MW, Peul WC. Diagnosis and treatment of sciatica. BMJ 2007;334:1313-7.

[2] Konstantinou K, Dunn KM. Sciatica: review of epidemiological studies and prevalence estimates. Spine 2008;33:2464-72.

[3] Leclerc A, Turbach F, Landre MF, et al. Personal and occupational predictors of sciatica in the Gazel cohort. Occup Med 2003:53:384-91.

[4] Stafford MA, Peng P, Hill DA. Sciatica: a review of history, epidemiology, pathogenesis, and the role of epidural steroid injection in management. Br J Anaesth 2007;99:461-73.

[5] Ha C, Roquelaure Y, Leclerc A, et al. The French musculoskeletal disorders surveillance program: Pays de la Loire network. Occup Environ Med 2009;66:471-9.

[6] Kaila-Kangas L, Leino-Arjas L, Karpinnen J, et al. History of physical exposures and clinically diagnosed sciatica among working and non working Finns aged 30 to 64. Spine 2009;34:964-9.

[7] Miranda H, Viikari-Juntura E, Martikainen R, et al. Individual factors, occupational loading, and physical exercise as predictors of sciatic pain. Spine 2002;27:1102-9.

[8] Seidler A, Bolm-Aurdorff U, Siol T, et al. Occupational risk factors for symptomatic lumbar disc herniation: a case-control study. Occup Environ Med 2003;60:821-30.

[9] Heliövaara M, Makela M, Knekt P, et al. Determinants of sciatica and low-back pain. Spine 1991;16:608-14.

[10] Heliövaara M. Risk factors for low back pain and sciatica. Ann Med 1989;21:257-64.

[11] Kelsey JL, Githens PB, O'Conner T, et al. Acute prolapsed-lumbar intervertebral disk. An epidemiologic study with special reference to driving automobiles and cigarette smoking. Spine 1984;9:608-13.
[12] Verger P, Viau A, Arnaud S, et al. Barriers to physician reporting of workers' compensation cases in France. Int J Occup Environ Health 2008;14:198-205.

[13] Cherkin DC, Deyo RA, Loeser JD, et al. An international comparison of back surgery rates. Spine 1994;19:1201-6.

[14] Guo HR, Tanaka S, Halperin E, et al. Back pain prevalence in US industry and estimates of lost workdays. Am J Public Health 1999;89:1029-35.

[15] Leino-Arjas P, Kaila-Kangas L, Keskimäki I, et al. Inpatients hospital care for lumbar intervertebral disc disorders in Finland in relation to education, occupational class, income and employment. Public Health 2002;116: 272-8.

[16] Rasmussen C, Nielsen GL, Hansen VK, et al. Rates of lumbar disc surgery before and after implementation of multidisciplinary non surgical spine clinics. Spine 2005;30:2469-73.

[17] Kleinbaum DG, Sullivan KM, Barker ND. A pocket guide to epidemiology. New York: Springer; 2007.

[18] Leino-Arjas P, Kaila-Kangas L, Kauppinen T, et al. Occupational exposures and inpatients hospital care for lumbar intervertebral disc disorders among Finns. Am J Indust Med 2004;46:513-20.

[19] Kaila-Kangas L, Keskimäki I, Notkola V, et al. How consistently distributed are the socioeconomic differences in severe back morbidity by age and gender? A population-based study of hospitalisation among Finnish employees. Occup Environ Med 2006;63:278-82.

[20] Punnet L. Socioeconomic differences in severe back morbidity. Occup Environ Med 2006;63:369-70.

[21] Latza U, Kohlman T, Deck R, et al. Can health care utilization explain the association between socioeconomic status and back pain? Spine 2004;29:1823-30.

[22] Leino-Arjas P, Hänninen K, Puska P. Socioeconomic variations in back pain and related pain in Finland. Eur J Epidemiol 1998;14:79-87.

[23] Luoma K, Riihimäki H, Raininko R, et al. Lumbar disc degeneration in relation to occupation. Scand J Work Environ Health 1998;24:358-66.

[24] Riihimäki H, Viikari-Juntura E, Moneta G, et al. Incidence of sciatic pain among men in machine operating, dynamic physical work, and sedentary work: a 3year follow-up. Spine 1994;19:138-42.

[25] Riihimäki H, Wickström G, Hänninen K, et al. Predictors of sciatic pain among concrete reinforcement workers and house painters - a 5-year follow-up. Scand J Work Environ Health 1989;15:415-23.

[26] Jörgensen S, Hein O, Gyntelberg F. Heavy lifting at work and risk of genita prolapse and herniated lumbar disc in assistant nurse. Occup Med 1994;44 46-9.

[27] Silverstein B, Viikari-Juntura E, Kalat J. Use of the prevention index to identify industries at high risk of work-related musculoskeletal disorders of the neck back, and upper extremities in Washington State, 1990-1998. Am J Ind Med 2002;41:149-69.

[28] Punnett L, Prüss-Ustün A, Nelson DI, et al. Estimating the global burden of low back pain attributable to combined occupational exposures. Am J Indust Med 2005;48:459-69. 